\title{
Regression of a nonfunctioning pituitary macroadenoma on the CDK4/6 inhibitor palbociclib: case report
}

\author{
Emily Anderson, MSPH, ${ }^{1}$ Robert S. Heller, MD, ${ }^{1}$ Ronald M. Lechan, MD, PhD, ${ }^{2}$ and \\ Carl B. Heilman, MD'
} 1Department of Neurosurgery, ${ }^{2}$ Division of Endocrinology, Diabetes, and Metabolism, Department of Medicine, Tufts Medical
Center, Boston, Massachusetts

\begin{abstract}
A 71-year-old female patient was referred in 2013 for evaluation of an asymptomatic nonsecreting pituitary adenoma. The adenoma, measuring $13 \mathrm{~mm}$ in height by $10 \mathrm{~mm}$ in width, was discovered incidentally on imaging in 2012. Biochemical testing demonstrated a nonfunctioning adenoma. Given the relatively small lesion size and the lack of symptoms, observation was preferred over surgical intervention. The patient was monitored with routine MRI, which until 2016 demonstrated minimal growth. In early 2016, the patient developed recurrence of metastatic breast cancer and was treated with palbociclib, a cyclin-dependent kinase (CDK) 4/6 inhibitor. This inhibitor acts on a pathway believed to be involved in pituitary adenoma tumorigenesis. One year after starting palbociclib, routine imaging demonstrated significant regression of her pituitary adenoma. The authors hypothesize that inhibition of the CDK4/6 pathway by palbociclib contributed to adenoma regression in this patient, and that palbociclib may represent a possible adjuvant therapy for the treatment of nonfunctioning pituitary adenomas.
\end{abstract}

https://thejns.org/doi/abs/10.3171/2018.2.FOCUS17660

KEYWORDS pituitary adenoma; palbociclib; CDK4/6 inhibitor

$\mathrm{P}$ ITUITARY adenomas are benign neoplasms that account for up to $15 \%$ of intracranial masses. ${ }^{29}$ Autopsy and radiological studies suggest that the prevalence of pituitary adenomas may be as high as $20 \%{ }^{7}$ Common presentations of patients with adenomas include neurological symptoms of headache or vision loss related to local compression, endocrinological dysfunction, or incidental diagnosis through imaging studies. ${ }^{36}$ Current treatment for pituitary adenomas is dependent on the secretory status of the tumor, size of the tumor, and patient symptoms. While a conservative approach consisting of serial MRI scans may be appropriate for nonfunctioning microadenomas $(<$ $1 \mathrm{~cm}$ ), a neurosurgical assessment is often warranted for patients with macroadenomas $(\geq 1 \mathrm{~cm})$ causing visual field deficits or neurological symptoms. ${ }^{10,21}$

The most common subtype of pituitary adenomas are prolactinomas $(46.2 \%-66.2 \%)$ followed by nonfunctioning adenomas (14.7\%-37\%). ${ }^{3,9,14,28} \mathrm{Up}$ to $95 \%$ of tumors occur sporadically, although there are several hereditary disorders that increase the risk of pituitary adenoma formation, such as multiple endocrine neoplasia types 1 and 4, Carney's complex, McCune-Albright syndrome, AIP mutations, and succinate dehydrogenase-related syndromes. ${ }^{23}$
There are many pathways implicated in sporadic pituitary adenoma formation, among which is the cyclin $\mathrm{D} /$ $\mathrm{CDK} / \mathrm{pRB}$ axis. ${ }^{25}$ In one study, mutations in components of this pathway were seen in $80 \%$ of pituitary adenomas. ${ }^{33}$ In this report, we present the case of a 71-year-old woman with a history of nonsecreting pituitary adenomas who was treated with a CDK4/6 inhibitor for metastatic breast cancer in 2016 and was subsequently found to have reduction of her pituitary adenoma.

\section{Case Report}

A 71-year-old woman was referred in 2013 for evaluation of a nonsecreting pituitary adenoma. The adenoma was discovered incidentally on MRI in 2012 during a workup for arm pain secondary to initiation of hydroxychloroquine for spontaneous recurrent angioedema. Other significant medical history for the patient included a C2-3 meningioma that had been resected in 2003, hypothyroidism treated with a thyroidectomy in 1978, hypercalcemia treated with a parathyroidectomy, and breast cancer treated with mastectomy in 1993 and 2005. Following her MRI, the patient was initially seen by her endocrinologist 
and subsequently referred to Tufts with a diagnosis of a nonsecreting pituitary adenoma.

At the time of her initial appointment at Tufts, the patient was asymptomatic, and formal ophthalmological visual field testing found no deficits. On MRI, her pituitary adenoma measured $13 \mathrm{~mm}$ in height and $10 \mathrm{~mm}$ in width and was elevated to the level of the undersurface of the optic chiasm.

The patient was next seen in 2015 following episodes of right ear pain. At the time, she denied headaches, polyuria, polydipsia, and any changes in peripheral vision. MRI was performed and did not show any changes when compared to the 2013 study. Subsequent MRI in 2016 showed a slight increase in size of the adenoma with slight uplifting of the optic chiasm. Ophthalmological testing confirmed no visual field deficits, and therefore observation was continued with follow-up formal visual field testing and MRI.

In early 2016, the patient was diagnosed with recurrent breast cancer at the site of her prior tumor location and started on a regimen of palbociclib therapy. In October 2016, the patient had 2 episodes of spinning and unsteadiness. MRI showed restricted diffusion in the left inferior cerebellum in the territory of the posterior inferior cerebellar artery, consistent with an acute ischemic infarction. Following these events, she was seen by the neurosurgery service in November 2016. At the time of this visit, she continued to deny polyuria, polydipsia, or headache. The tumor remained stable in size, and, because the patient was asymptomatic and was being treated for breast cancer recurrence, the decision was made to follow up in 6 months.

Six months later, in 2017 repeat MRI showed that the patient's adenoma had significantly decreased in size, now measuring $8 \mathrm{~mm}$ in height by $8 \mathrm{~mm}$ in width (Fig. 1). The tumor was no longer touching the chiasm or optic nerves and did not extend more rostral than the diaphragma sellae. The patient denied any sudden severe headaches to suggest pituitary apoplexy. At the time of this MRI study, she had been on palbociclib for approximately 1 year.

\section{Discussion}

Pituitary adenomas are the most common cause of sellar masses in patients 30 years of age and older. ${ }^{11,16}$ Treatment is dependent on secretory status of the tumor, size of the tumor, and patient symptoms. Standard of care for symptomatic prolactinomas, the most common type of pituitary adenoma, is medical management, although resection remains an option in those patients unable to tolerate dopamine agonist therapy. Conversely, standard of care for larger and/or symptomatic nonsecreting adenomas is resection.

Although pathways involved in the pathogenesis of nonsecreting adenomas have been studied, medical management of nonfunctioning pituitary adenomas has been limited. Two classes of drugs that have been used in the treatment of pituitary adenomas are somatostatin analogs and dopamine agonists. These drugs take advantage of the presence of somatostatin and dopamine receptors on the surface of some nonfunctioning pituitary adenomas. . $^{15,27,34}$ Studies have shown that up to $67 \%$ of nonfunctioning pitu-
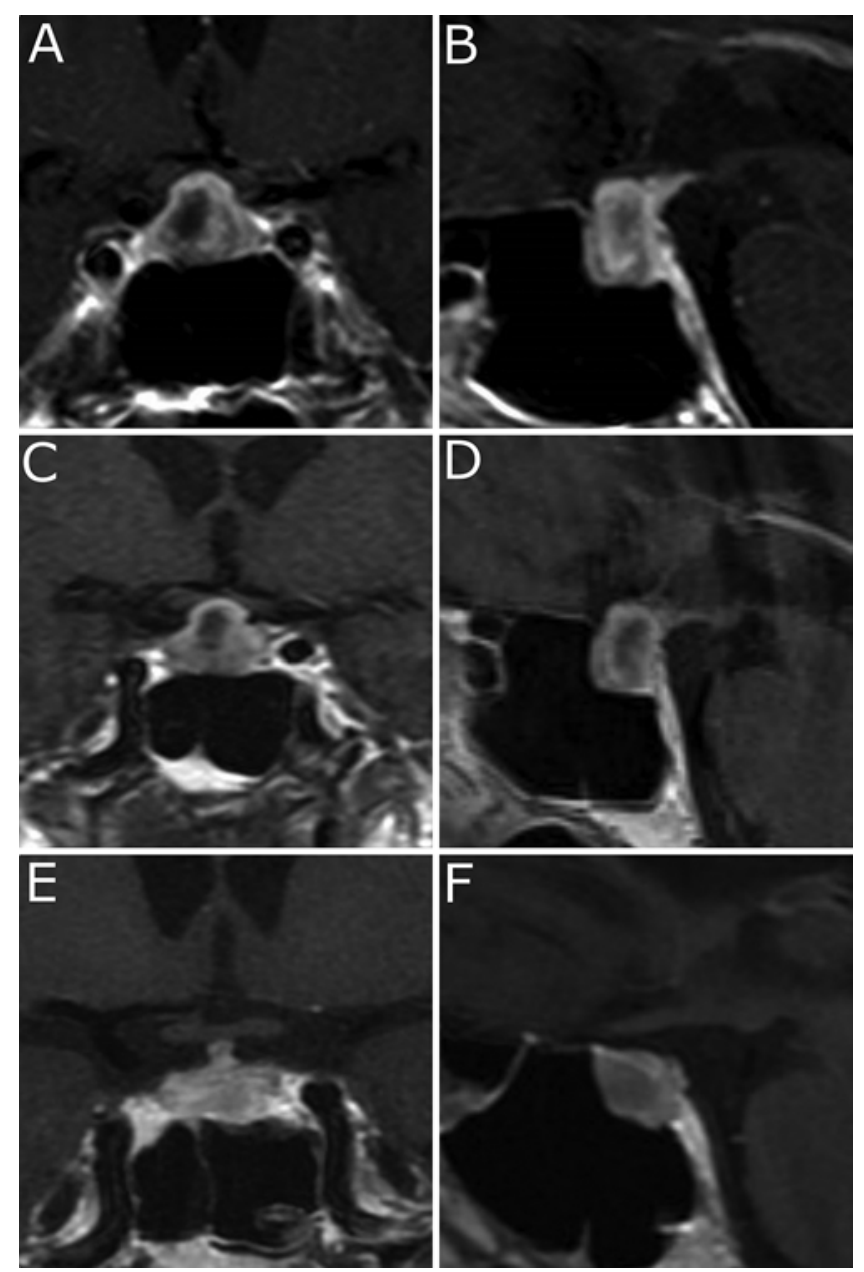

FIG. 1. Postgadolinium T1-weighted MR images in the coronal (left panels) and sagittal (right panels) planes. A and B: Images from 2015, demonstrating a pituitary macroadenoma contacting the undersurface of the optic chiasm with a cystic component. C and D: In 2016, shortly before the start of palbociclib therapy, the adenoma is stable in comparison to earlier. E and F: One year later in 2017, the macroadenoma has significantly reduced in size, with near resolution of the suprasellar component.

itary adenomas express D2 receptors and up to $100 \%$ may express one type of somatostatin receptor. . $^{1,24,26}$

In vitro studies of somatostatin analogs and dopamine agonists have shown that both classes of drugs are effective in promoting cell death. In a study by Padova et al., somatostatin analogs specific for the somatostatin 2 (Sst2) receptor reduced cell viability by $20 \%-80 \%$ in nonfunctioning pituitary adenomas exhibiting Sst2 expression. ${ }^{26}$ Similarly, in vitro studies of bromocriptine, a D2 receptor antagonist, reduced cell viability in $60 \%$ of nonfunctioning pituitary adenoma cell cultures..$^{15}$

In vivo effects of these drugs have been varied. Octreotide, a somatostatin receptor analog, improved visual fields in patients with pituitary adenomas, although it had no effect on tumor size. ${ }^{4}$ In a study by Bevan et al., treatment with bromocriptine for 1 year resulted in adenoma reduction in only $15 \%$ of patients. ${ }^{1}$ The most effective of these drugs in vivo has been cabergoline, a D2 dopamine 
agonist. In a study by Pivonello et al., treatment with cabergoline resulted in tumor shrinkage in $56 \%$ of patients. Unsurprisingly, cabergoline was more effective in tumors expressing D2 receptors. ${ }^{27}$ These studies demonstrate that while medications can aid in tumor reduction, there are mixed responses and the response to treatment largely depends on receptor expression of the cell.

In the case presented herein, the patient had a history of an asymptomatic nonsecreting pituitary adenoma. After a year of treatment with palbociclib, a CDK4/6 inhibitor, for metastatic breast cancer, her pituitary tumor decreased in size. Although the pathways involved in the pathogenesis of this specific tumor are unknown, the pathway inhibited by palbociclib is frequently found to be involved in the pathogenesis of pituitary adenomas. Therefore, there is reason to believe that the medical therapy used for the treatment of the patient's breast cancer may have played a role in size reduction of the adenoma.

Palbociclib, in combination with letrozole, was granted FDA accelerated approval in 2015 for initial endocrinebased treatment of estrogen receptor-positive, HER2-negative advanced breast cancers in postmenopausal women. ${ }^{2,32}$ Palbociclib, like other CDK4/6 inhibitors, targets the cyclin $\mathrm{D} / \mathrm{CDK} /$ retinoblastoma protein $(\mathrm{pRB})$ pathway. In normally functioning mammalian cells, CDK 4 and 6 form a complex with cyclin D1 to initiate phosphorylation of retinoblastoma tumor suppressor protein $(\mathrm{Rb})$. When $\mathrm{Rb}$ is phosphorylated, it is unable to suppress E2F, a protein required for progression from $\mathrm{G}_{1}$ to $\mathrm{S}$ of the cell cycle, and thus the cell initiates cell division. However, when p16, a CDK inhibitor, is activated, the CDK4/6 and cyclin complex is inhibited, resulting in a hypophosphorylated pRB. When hypophosphorylated, pRB inhibits E2F, thus halting progression through the cell cycle. In malignancy, this pathway is frequently disrupted, leading to unregulated progression through the cell cycle. ${ }^{6,31}$

In preclinical studies, palbociclib has shown activity against a variety of cell lines, including colon, breast, glioblastoma, and prostate cancer. ${ }^{12}$ Given that mutations in the cyclin $\mathrm{D} / \mathrm{CDK} / \mathrm{pRb}$ pathways have been seen in up to $90 \%$ of all cancers, these results are encouraging. ${ }^{22,30}$ With respect to the cyclin/CDK/pRb pathway in pituitary adenoma formation, inactivation of $\mathrm{Rb}$ in murine models has been associated with an increased risk of developing pituitary adenomas. ${ }^{19,37}$

Studies on human pituitary adenomas have confirmed the involvement of this pathway in pituitary tumorigenesis. In a study by Simpson et al., abnormal expression of pRb, p16, or cyclin D1 was seen in $80 \%$ of tumors. ${ }^{33}$ Two additional studies by Jordan et al. and Hibberts et al. independently demonstrated overexpression of cyclin D1 in $67 \%$ of nonfunctioning pituitary adenomas. ${ }^{18,20}$ Furthermore, this pathway has been implicated in pituitary adenoma recurrence following resection. ${ }^{17}$ Given the tumor regression seen in the patient presented herein following treatment with a cyclin 4/6 inhibitor, we hypothesize that the medication contributed to the regression. It is notable that the adenoma contained a moderately sized cystic component prior to palbociclib therapy. Resolution of this cystic component likely contributed significantly to the reduced overall size of the adenoma. Whether palbociclib is more effective against cystic versus solid components of tumors as well as the mechanism underlying this possibility remains uncertain and is an area of future research.

Although there is evidence to suggest that palbociclib might have affected tumor reduction in this case, there may have been other contributing factors. It is possible that pituitary apoplexy occurred in this patient, although it is unlikely given the lack of clinical findings to suggest the occurrence of apoplexy between 2016 and 2017. Additionally, the pituitary adenoma could have spontaneously regressed in this patient. Spontaneous regression of nonfunctioning pituitary macroadenomas has been reported in approximately $10 \%$ of tumors. ${ }^{5}$ It is also possible that this patient might have been particularly susceptible to a targeted therapy such as palbociclib. Given that she developed several separate primary tumors (breast, meningioma, and pituitary), this raises the possibility of a genetic predisposition to tumor development from a germline mutation in the CDK4/6 pathway.

The radiographic appearance of the lesion in the pituitary gland, the timeline of slow growth over several years, and the location of the lesion in the anterior pituitary gland suggest that this lesion is most likely a pituitary adenoma. As this patient did not undergo resection, pathologic confirmation was not obtained. However, metastases to the anterior pituitary gland without involvement of the bony sella would be unusual, with lesions in the pituitary stalk and median eminence being more common. ${ }^{8}$ Patients in this scenario generally present with diabetes insipidus, which was not present in our patient. It remains possible, yet unlikely, that this lesion was a slowgrowing breast cancer metastasis rather than a pituitary adenoma, although the available evidence points toward the latter.

While this case suggests that CDK4/6 inhibitors may have a role in the treatment of pituitary adenomas by promoting tumor regression, it is also possible that these inhibitors could be beneficial as adjuvant treatment in prevention of tumor recurrence or as a means to prevent tumor growth following primary surgical treatment. Tumor recurrence within 5 years of resection has been observed in anywhere from $15 \%$ to $66 \%$ of patients. ${ }^{35}$ As mentioned earlier, involvement of the cyclin/CDK/pRb pathway has been implicated in tumor recurrence. ${ }^{17}$ Thus, use of CD4/6 inhibitors may have a multifactorial role in medical management of nonfunctioning pituitary adenomas.

\section{References}

1. Bevan JS, Webster J, Burke CW, Scanlon MF: Dopamine agonists and pituitary tumor shrinkage. Endocr Rev 13:220-240, 1992

2. Clark AS, Karasic TB, DeMichele A, Vaughn DJ, O'Hara M, Perini R, et al: Palbociclib (PD0332991) - a selective and potent cyclin-dependent kinase inhibitor: a review of pharmacodynamics and clinical development. JAMA Oncol 2:253-260, 2016

3. Daly AF, Rixhon M, Adam C, Dempegioti A, Tichomirowa MA, Beckers A: High prevalence of pituitary adenomas: a cross-sectional study in the province of Liege, Belgium. J Clin Endocrinol Metab 91:4769-4775, 2006

4. de Bruin TW, Kwekkeboom DJ, Van't Verlaat JW, Reubi JC, Krenning EP, Lamberts SW, et al: Clinically nonfunction- 
ing pituitary adenoma and octreotide response to long term high dose treatment, and studies in vitro. J Clin Endocrinol Metab 75:1310-1317, 1992

5. Dekkers OM, Pereira AM, Romijn JA: Treatment and followup of clinically nonfunctioning pituitary macroadenomas. J Clin Endocrinol Metab 93:3717-3726, 2008

6. Dowdy SF, Hinds PW, Louie K, Reed SI, Arnold A, Weinberg RA: Physical interaction of the retinoblastoma protein with human D cyclins. Cell 73:499-511, 1993

7. Ezzat S, Asa SL, Couldwell WT, Barr CE, Dodge WE, Vance ML, et al: The prevalence of pituitary adenomas: a systematic review. Cancer 101:613-619, 2004

8. Fassett DR, Couldwell WT: Metastases to the pituitary gland. Neurosurg Focus 16(4):E8, 2004

9. Fernandez A, Karavitaki N, Wass JA: Prevalence of pituitary adenomas: a community-based, cross-sectional study in Banbury (Oxfordshire, UK). Clin Endocrinol (Oxf) 72:377382,2010

10. Freda PU, Beckers AM, Katznelson L, Molitch ME, Montori VM, Post KD, et al: Pituitary incidentaloma: an endocrine society clinical practice guideline. J Clin Endocrinol Metab 96:894-904, 2011

11. Freda PU, Post KD: Differential diagnosis of sellar masses. Endocrinol Metab Clin North Am 28:81-117, vi, 1999

12. Fry DW, Harvey PJ, Keller PR, Elliott WL, Meade M, Trachet E, et al: Specific inhibition of cyclin-dependent kinase 4/6 by PD 0332991 and associated antitumor activity in human tumor xenografts. Mol Cancer Ther 3:1427-1438, 2004

13. Greenman Y, Melmed S: Expression of three somatostatin receptor subtypes in pituitary adenomas: evidence for preferential SSTR5 expression in the mammosomatotroph lineage. J Clin Endocrinol Metab 79:724-729, 1994

14. Gruppetta M, Mercieca C, Vassallo J: Prevalence and incidence of pituitary adenomas: a population based study in Malta. Pituitary 16:545-553, 2013

15. Gruszka A, Kunert-Radek J, Radek A, Pisarek H, Taylor J, Dong JZ, et al: The effect of selective sst1, sst2, sst5 somatostatin receptors agonists, a somatostatin/dopamine (SST/DA) chimera and bromocriptine on the "clinically non-functioning" pituitary adenomas in vitro. Life Sci 78:689-693, 2006

16. Gsponer J, De Tribolet N, Déruaz JP, Janzer R, Uské A, Mirimanoff RO, et al: Diagnosis, treatment, and outcome of pituitary tumors and other abnormal intrasellar masses. Retrospective analysis of 353 patients. Medicine (Baltimore) 78:236-269, 1999

17. Hewedi IH, Osman WM, El Mahdy MM: Differential expression of cyclin D1 in human pituitary tumors: relation to MIB-1 and p27/Kip1 labeling indices. J Egypt Natl Canc Inst 23:171-179, 2011

18. Hibberts NA, Simpson DJ, Bicknell JE, Broome JC, Hoban PR, Clayton RN, et al: Analysis of cyclin D1 (CCND1) allelic imbalance and overexpression in sporadic human pituitary tumors. Clin Cancer Res 5:2133-2139, 1999

19. Jacks T, Fazeli A, Schmitt EM, Bronson RT, Goodell MA, Weinberg RA: Effects of an Rb mutation in the mouse. Nature 359:295-300, 1992

20. Jordan S, Lidhar K, Korbonits M, Lowe DG, Grossman AB: Cyclin D and cyclin E expression in normal and adenomatous pituitary. Eur J Endocrinol 143:R1-R6, 2000

21. Lake MG, Krook LS, Cruz SV: Pituitary adenomas: an overview. Am Fam Physician 88:319-327, 2013

22. Malumbres M, Barbacid M: Cell cycle, CDKs and cancer: a changing paradigm. Nat Rev Cancer 9:153-166, 2009

23. Marques P, Korbonits M: Genetic aspects of pituitary adenomas. Endocrinol Metab Clin North Am 46:335-374, 2017

24. Nielsen S, Mellemkjaer S, Rasmussen LM, Ledet T, Olsen N, Bojsen-Møller M, et al: Expression of somatostatin receptors on human pituitary adenomas in vivo and ex vivo. J Endocrinol Invest 24:430-437, 2001
25. Ogino A, Yoshino A, Katayama Y, Watanabe T, Ota T, Komine C, et al: The p15(INK4b)/p16(INK4a)/RB1 pathway is frequently deregulated in human pituitary adenomas. J Neuropathol Exp Neurol 64:398-403, 2005

26. Padova H, Rubinfeld H, Hadani M, Cohen ZR, Nass D, Taylor JE, et al: Effects of selective somatostatin analogs and cortistatin on cell viability in cultured human non-functioning pituitary adenomas. Mol Cell Endocrinol 286:214-218, 2008

27. Pivonello R, Matrone C, Filippella M, Cavallo LM, Di Somma C, Cappabianca P, et al: Dopamine receptor expression and function in clinically nonfunctioning pituitary tumors: comparison with the effectiveness of cabergoline treatment. J Clin Endocrinol Metab 89:1674-1683, 2004

28. Raappana A, Koivukangas J, Ebeling T, Pirilä T: Incidence of pituitary adenomas in Northern Finland in 1992-2007. J Clin Endocrinol Metab 95:4268-4275, 2010

29. Scheithauer BW, Gaffey TA, Lloyd RV, Sebo TJ, Kovacs KT, Horvath E, et al: Pathobiology of pituitary adenomas and carcinomas. Neurosurgery 59:341-353, 2006

30. Sellers WR, Kaelin WG Jr: Role of the retinoblastoma protein in the pathogenesis of human cancer. J Clin Oncol 15:3301-3312, 1997

31. Serrano M, Lee H, Chin L, Cordon-Cardo C, Beach D, DePinho RA: Role of the INK4a locus in tumor suppression and cell mortality. Cell 85:27-37, 1996

32. Sherr CJ, Beach D, Shapiro GI: Targeting CDK4 and CDK6: from discovery to therapy. Cancer Discov 6:353-367, 2016

33. Simpson DJ, Frost SJ, Bicknell JE, Broome JC, McNicol AM, Clayton RN, et al: Aberrant expression of $\mathrm{G}_{1} / \mathrm{S}$ regulators is a frequent event in sporadic pituitary adenomas. Carcinogenesis 22:1149-1154, 2001

34. Taboada GF, Luque RM, Bastos W, Guimarães RF, Marcondes JB, Chimelli LM, et al: Quantitative analysis of somatostatin receptor subtype (SSTR1-5) gene expression levels in somatotropinomas and non-functioning pituitary adenomas. Eur J Endocrinol 156:65-74, 2007

35. Tampourlou M, Ntali G, Ahmed S, Arlt W, Ayuk J, Byrne $\mathrm{JV}$, et al: outcome of nonfunctioning pituitary adenomas that regrow after primary treatment: a study from two large UK centers. J Clin Endocrinol Metab 102:1889-1897, 2017

36. Vargas G, Gonzalez B, Ramirez C, Ferreira A, Espinosa E, Mendoza V, et al: Clinical characteristics and treatment outcome of 485 patients with nonfunctioning pituitary macroadenomas. Int J Endocrinol 2015:756069, 2015

37. Williams BO, Schmitt EM, Remington L, Bronson RT, Albert DM, Weinberg RA, et al: Extensive contribution of $\mathrm{Rb}$-deficient cells to adult chimeric mice with limited histopathological consequences. EMBO J 13:4251-4259, 1994

\section{Disclosures}

The authors report no conflict of interest concerning the materials or methods used in this study or the findings specified in this paper.

\section{Author Contributions}

Conception and design: Heilman, Lechan. Acquisition of data: Anderson, Heller. Analysis and interpretation of data: all authors. Drafting the article: all authors. Critically revising the article: all authors. Reviewed submitted version of manuscript: Heilman, Anderson, Lechan. Approved the final version of the manuscript on behalf of all authors: Heilman. Study supervision: Heilman, Lechan.

\section{Correspondence}

Carl B. Heilman: Tufts Medical Center, Boston, MA. cheilman@ tuftsmedicalcenter.org. 